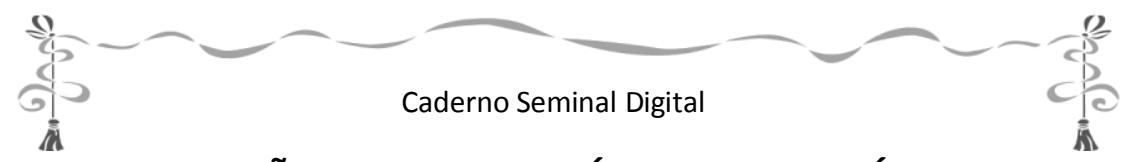

\title{
PRODUÇÃO DE UM DICIONÁRIO TERMINOLÓGICO MULTILÍNGUE DE AGENCIAMENTO DE VIAGENS E TURISMO: DISCUSSÃO ACERCA DO TERMO AGÊNCIA
}

PRODUCTION OF A MULTILINGUAL TERMINOLOGICAL DICTIONARY OF TOUR OPERATING: DISCUSSION ABOUT THE TERM AGENCY

Maria Aparecida Barbosa (DL/FFLCH/USP) Claudia Maria Astorino (UFSCar-DL/FFLCH/USP)

Resumo: Este estudo é parte da pesquisa de doutorado de Astorino, sob a orientação de Barbosa, que tem como tema a terminologia de Agenciamento de Viagens e Turismo, uma subárea do Turismo, na sua condição de atividade social e econômica. O escopo teórico dessa investigação é a discussão sobre a terminologia da linguagem de Agenciamento de Viagens e Turismo, ao passo que o objetivo prático é a produção de um dicionário terminológico desta subárea, em quatro idiomas: português, inglês, espanhol e italiano. A seleção dos termos foi realizada a partir de uma pesquisa em duas obras acadêmicas selecionadas, escritas em português brasileiro, e voltadas aos cursos de bacharelado em Turismo de Instituições de Ensino Superior. Posteriormente, buscaram-se equivalências desses termos, em obras análogas, escritas em inglês, espanhol e italiano duas para cada um destes idiomas - as quais, juntamente com as obras em português, compuseram o corpus de extração da pesquisa. Ao final da coleta, chegou-se a um total de cerca de 2000 termos em português, dado este que impossibilitaria a produção do dicionário terminológico supracitado, em função do elevado número de análises terminológicas, definições e equivalências nos três idiomas estrangeiros, que deveriam ser elaboradas, o que levou, então, a uma nova seleção - baseada nas características

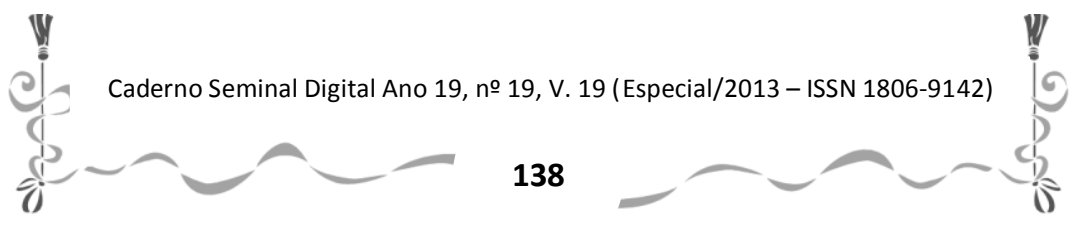


específicas da linguagem do Turismo - para se chegar ao número razoável de 650 termos. $O$ presente trabalho objetiva discutir alguns dos resultados para os termos derivados do hiperônimo agência.

Palavras-chave: Linguagem de Agenciamento de Viagens e Turismo. Agência. Conceitos e Termos. Dicionário Terminológico Multilíngue.

Abstract: This study is part of the doctoral research of Astorino, under the guidance of Barbosa, whose theme is the terminology of Tour Operating, a subarea of Tourism, in its condition of social and economic activity. The theoretical scope of this research is to discuss the terminology of Tour Operating language, while the practical goal is the production of a terminological dictionary of this subarea, in four languages: Portuguese, English, Spanish and Italian. The selection of the terms was performed from a survey in two selected works, written in Brazilian Portuguese, geared to the bachelor degree in Tourism and therefore used in universities. Subsequently, these terms were researched in similar works, written in English, Spanish and Italian - two for each of these languages - which, along with the works in Portuguese, composed the corpus extraction of the research. At the end of the collection, it reached a total of about 2000 terms in Portuguese. As this result would not facilitate the production of the terminological dictionary mentioned above, due to the high number of terminology analyzes, definitions and equivalences in the three foreign languages, a new selection was conducted - based on the specific characteristics of the language of Tourism - to get to a reasonable number of 650 terms. This paper discusses some of the results for the terms derived from the hyperonym agency.

Keywords: Tour Operating Language. Agency. Concept and Terms.

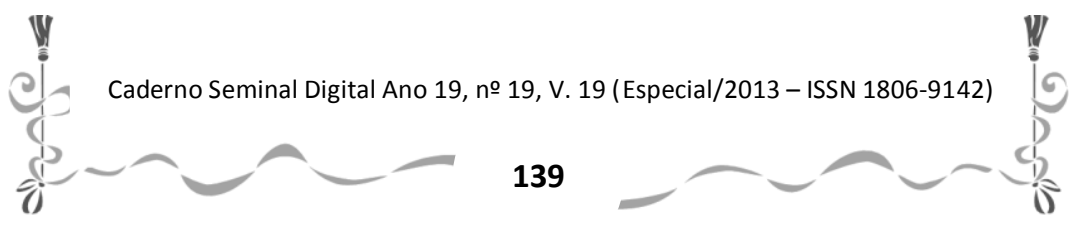


Caderno Seminal Digital

(1)

Multilingual Terminological Dictionary.

\section{INTRODUÇÃO}

Este estudo é parte da pesquisa de doutorado de Astorino, sob a orientação de Barbosa, que tem como tema a terminologia de Agenciamento de Viagens e Turismo, uma subárea do Turismo, na sua condição de atividade social e econômica. $O$ escopo teórico dessa investigação é a discussão sobre a terminologia da linguagem de Agenciamento de Viagens e Turismo, ao passo que o objetivo prático é a produção de um dicionário terminológico desta subárea, em quatro idiomas: português, inglês, espanhol e italiano. A seleção dos termos foi realizada a partir de uma pesquisa em duas obras acadêmicas selecionadas, escritas em português brasileiro, e voltadas aos cursos de bacharelado em Turismo de Instituições de Ensino Superior. Posteriormente, buscaramse equivalências desses termos, em obras análogas, escritas em inglês, espanhol e italiano - duas para cada um destes idiomas - as quais, juntamente com as obras em português, compuseram o corpus de extração da pesquisa. Ao final da coleta, chegou-se a um total de cerca de 2000 termos em português, dado este que impossibilitaria a produção do dicionário terminológico supracitado, em função do elevado número de análises terminológicas, definições e equivalências nos três idiomas estrangeiros, que deveriam ser elaboradas, o que levou, então, a uma nova seleção - baseada nas características específicas da linguagem do Turismo - para se

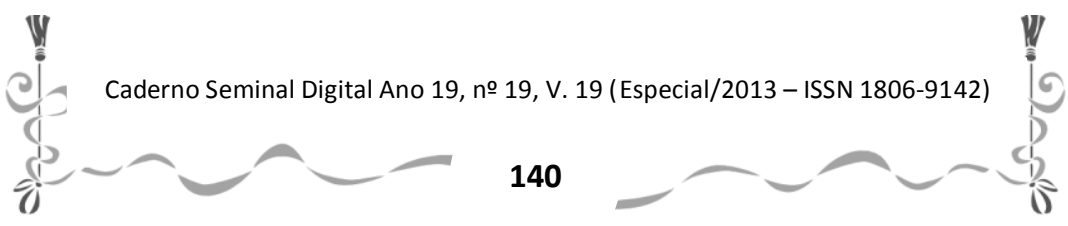


Caderno Seminal Digital

Â.

chegar ao número razoável de 650 termos. O presente trabalho objetiva discutir alguns dos resultados para os termos derivados do hiperônimo agência. Para se proceder à pesquisa, foram consideradas as seguintes hipóteses, que a norteariam: i) há uso de sinônimos para conceitos iguais; ii) registra-se uso de antônimos; iii) há influência da língua inglesa na formação dos termos em português brasileiro; iv) há influência da língua espanhola na formação dos termos em português brasileiro.

\section{METODOLOGIA}

No que tange ao aspecto teórico, esta pesquisa norteia-se pela Teoria Comunicativa da Terminologia (TCT), proposta e difundida na década de 1990, pela linguista Maria Teresa Cabré (1993). A escolha desta teoria se deu em virtude de seu caráter descritivo, o qual contrasta com o caráter prescritivo da Teoria Geral da Terminologia, sustentada pelo engenheiro austríaco Eugen Wüster. A metodologia constituiu-se de sete etapas de trabalho, de modo a ordenar os procedimentos de investigação, seleção e análise. Na primeira etapa, foi realizada a seleção do corpora, dividido em dois blocos: um corpus de extração e um corpus de comparação. $O$ primeiro formou-se por oito obras acadêmicas selecionadas, duas escritas em português brasileiro, duas em inglês, duas em espanhol e duas em italiano. Cabe esclarecer que estas oito obras acadêmicas juntas, agrupadas em quatro grupos de duas para cada idioma, compuseram o corpus de extração. Segundo a classificação de Sardinha (2004, pp. 20-22), este primeiro corpus selecionado pode ser considerado: i) escrito, quanto ao modo; ii) contemporâneo, uma vez

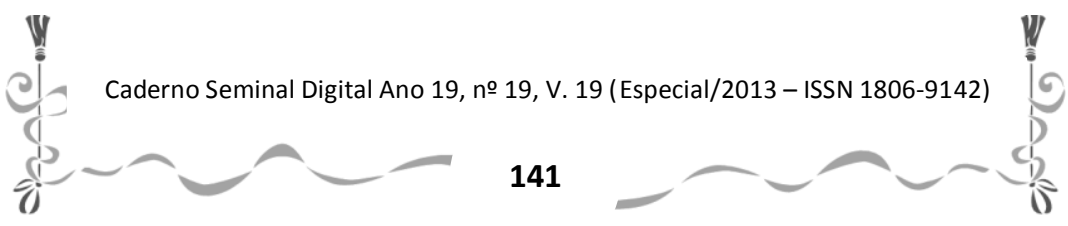


que representa a atualidade; iii) estático, por se tratar de material publicado de forma impressa, portanto, não passível de mudanças imediatas, pois somente uma reedição poderia implicar eventuais mudanças; iv) especializado, quanto ao seu conteúdo, porque é orientado a estudiosos do Turismo, como área do conhecimento; v) de língua nativa, presumindo que os autores são falantes nativos de cada um dos idiomas, nos quais os livros foram publicados; vi) comparável, isto é, constituído por textos originais pertencentes ao mesmo gênero (textos acadêmicos de Turismo), embora haja pequenas diferenças estruturais (na macroestrutura) entre uma obra selecionada e outra; e, por fim, vii) plurilíngue, pois é constituído de textos de línguas distintas. Com vistas à formação do corpus de comparação, após uma investigação acerca de dicionários terminológicos de turismo, escolheram-se o Dicionário de Turismo, de Robério Braga (monolíngue, escrito em português brasileiro) e o Dicciionari D’Hoteleria i Turisme Termcat (multilíngue, escrito em catalão, com equivalências em espanhol (castelhano), inglês, francês e alemão. Com estas duas obras, estava formado, portanto, o corpus de comparação. Posteriormente, na segunda etapa, foi realizada uma criteriosa leitura em busca de candidatos a termos, nas obras escritas em português (TOMELIN, 2001 e BRAGA, 2007a), as quais são voltadas ao curso de bacharelado em Turismo de Instituições de Ensino Superior, no Brasil. Esses termos foram, inicialmente, destacados, dentro de cada um dos textos, para serem, num segundo momento, coletados. A coleta foi realizada manualmente, posto que o número reduzido das obras investigadas (duas) não justificava a adoção da Linguística do Corpus nem da Linguística Computacional. A especialização profissional da doutoranda

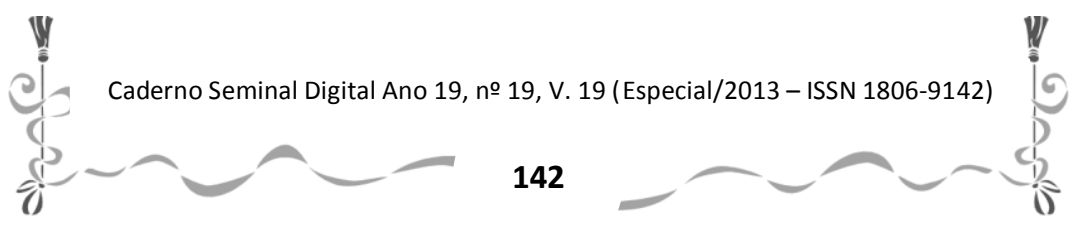


na subárea de Agenciamento de Viagens e Turismo, inclusive como docente desta disciplina, no curso de bacharelado em Turismo da Universidade Federal de São Carlos, facilitou a seleção dos vocábulos candidatos a termos. Em seguida, na terceira etapa, os termos coletados foram incorporados a uma lista. Para uma melhor organização, preencheu-se uma lista para cada uma das duas obras acadêmicas em português brasileiro. Somando-se as duas listas, chegou-se a um total de mais de 2000 termos, número este que seria exagerado para a proposta da referida tese de doutorado. Percebeu-se, então, a necessidade de reduzir o número de termos, de forma a viabilizar as análises terminológicas e a elaboração das definições e das equivalências nos três idiomas estrangeiros, processo este que seria caracterizado como a quarta etapa. A princípio, para se chegar ao número razoável de 650 termos, estabeleceu-se como critério o número de ocorrências. No entanto, ao longo da análise, percebeu-se que se fossem mantidos somente aqueles com maior ocorrência, perder-se-ia no aspecto da pluralidade de termos para designar um mesmo conceito. Assim sendo, além do quesito ocorrência, foi adotado também o critério das relações hiperônimo/hipônimos e sinonímia/antonímia. Na etapa sucessiva, a quinta, buscaram-se os termos, nas obras escritas em inglês, espanhol e italiano do corpus de extração, e compilou-se uma lista para cada uma das línguas estrangeiras. A sexta etapa constituiu-se do preenchimento de uma ficha terminológica para cada um dos termos, isoladamente, usando-se, para este fim, o modelo desenvolvido por Barbosa (s/d, p. 18), adaptado. Nesta ficha terminológica, cada termo foi analisado dentro do seu contexto, sendo que os dois primeiros contextos eram extraídos das obras acadêmicas em português, que faziam parte do

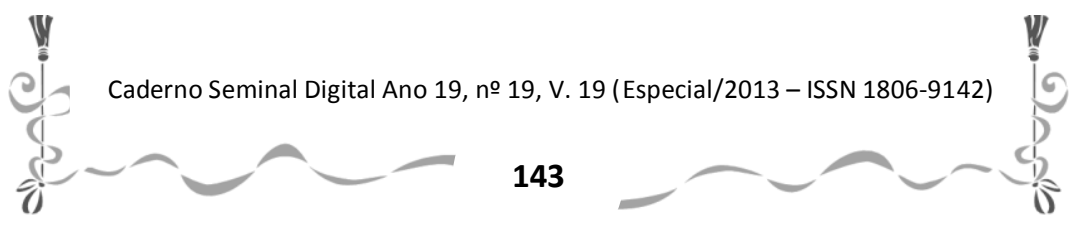


corpus de extração, e os dois últimos equivaliam às definições de cada um dos dicionários especializados selecionados, pertencentes ao corpus de comparação. Ainda nesta etapa, destacaram-se os traços conceituais de cada termo, dentro da sua contextualização. Com base na comparação de tais traços conceituais, chegava-se, enfim, à definição para cada termo analisado. Sucessivamente, procedia-se à pesquisa de equivalentes em inglês, espanhol e italiano, para o termo sob análise, a partir da lista de termos nos idiomas estrangeiros. Dessa maneira, com a ficha terminológica concluída, findava-se, também, a sexta etapa. A sétima e última etapa da tese de doutorado é a organização do dicionário terminológico, enquanto a etapa final deste estudo específico, que aqui se apresenta, consistiu numa análise e discussão do termo hiperônimo agência e de seus derivados.

\section{RESULTADOS}

Foram encontrados mais de 2000 termos nos dois textos em língua portuguesa, que fazem parte do corpus de extração. A partir desse número, foi realizada uma nova seleção, de modo a reduzir os termos para um total de 650 . Esta segunda seleção levou em consideração, sobretudo, relações de hiperonímia/hiponímia e sinonímia/antonímia. Dentro deste novo universo que se configurou, os termos que mais apresentaram ocorrências foram agência, agência de viagens e operadora (vide tabela 1 ), o que talvez explique o fato de que esses estejam entre os termos que mais apresentam sinônimos (vide tabela 2).

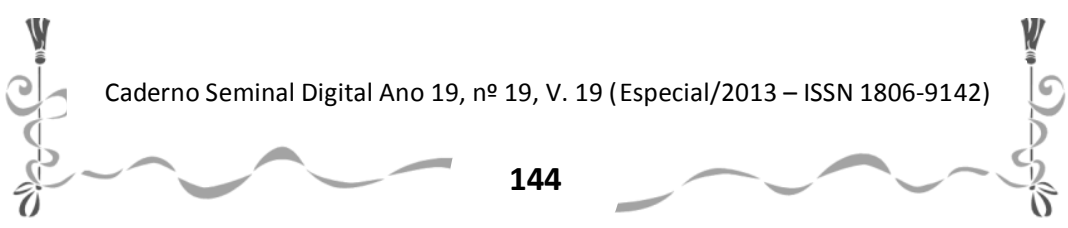




\begin{tabular}{|l|l|l|}
\hline TERMO & $\begin{array}{l}\text { No DE OCORRÊNCIAS } \\
\text { TOMELIN }\end{array}$ & $\begin{array}{l}\text { No DE OCORRÊNCIAS } \\
\text { BRAGA }\end{array}$ \\
\hline Agência & 96 & 249 \\
\hline Agência de viagens & 53 & 145 \\
\hline Operadora & 28 & 189 \\
\hline
\end{tabular}

Tabela 1: Termos que mais apresentaram ocorrências.

\begin{tabular}{|l|l|}
\hline TERMO & № DE SINÔNIMOS \\
\hline Agência & 6 \\
\hline Agência de viagens & 7 \\
\hline Operadora & 9 \\
\hline
\end{tabular}

Tabela 2: Número de sinônimos dos termos com maior ocorrência, nas duas obras pesquisadas.

\section{DISCUSSÃO DOS RESULTADOS}

O principal hiperônimo da subárea de Agenciamento de Viagens e Turismo é o termo agência, pois pode designar qualquer tipo de empresa que atua no âmbito da organização e comercialização de viagens, independentemente de sua modalidade, tipo de negócios, área de atuação, etc. 0 hiperônimo agência é uma forma simplificada do sintagma composto agência de turismo e pode ser usado em substituição a este último. Tal substituição pode ser comprovada no seguinte trecho:

Caderno Seminal Digital Ano 19, no 19, V. 19 (Especial/2013 - ISSN 1806-9142) 


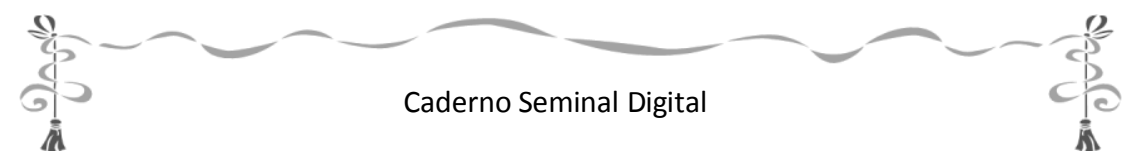

A possibilidade do acesso das <agências de turismo> aos CRS foi a maneira que as companhias aéreas encontraram para ampliar a distribuição e venda de assentos em seus voos, uma vez que esses sistemas traziam praticidade e rapidez aos processos, e as <agências> podiam atender mais clientes, em vez de perder tempo fazendo ligações telefônicas (SANTOS \& MURAD JR, 2207, p. 106).

Ainda em reação ao hiperônimo agência, em razão de seus numerosos derivados, inicialmente, para proceder à elaboração do dicionário terminológico, pensou-se em rejeitar boa parte dos termos afins e manter somente os que foram encontrados em ocorrências mais numerosas. No entanto, logo se percebeu que esse corte representaria uma grande perda na análise da terminologia de Agenciamento de Viagens e Turismo, a qual, pelo que se constatou e relatou, tem a sinonímia como uma de suas características mais marcantes. Ademais, vale ressaltar que agência é justamente o termo que dá origem aos demais, de onde se deduz que todos os outros têm, em si, a noção de agência embutida, independentemente das outras noções que a essa se agregam. Tomando como exemplo o termo composto agência de viagens emissiva especializada em eventos, constata-se que o termo agência de viagens tem embutido em si o conceito de agência; por sua vez, agência de viagens emissiva tem embutido o conceito de agência de viagens, e, por fim, agência de viagens emissiva especializada em eventos tem embutido em si o conceito de agência de viagens emissiva, de

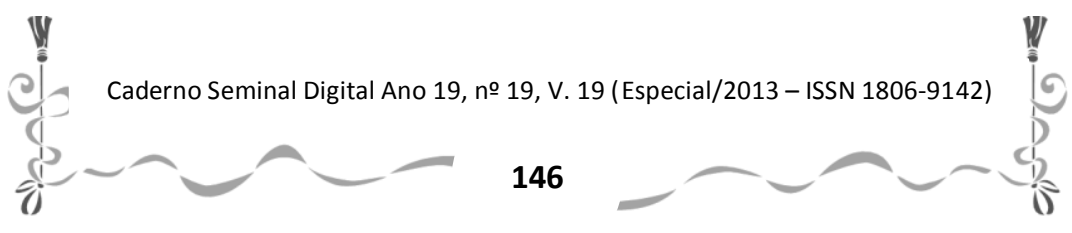


Caderno Seminal Digital

(16

onde se deduz que um termo composto da subárea de Agenciamento de Viagens e Turismo acumula todos os conceitos dos termos que contribuíram para a formação do sintagma composto.

Passando-se, agora, à análise do termo agência de viagens, nota-se que este apresenta um sinônimo que pode ser considerado perfeito, agência de viagem, pois embora o primeiro seja bem mais frequente que o segundo, ambos são intercambiáveis em quaisquer contextos. Todavia, deve-se esclarecer que não há uma padronização rígida em relação ao uso do terceiro elemento do termo, no singular ou no plural, viagem/viagens, como se pode notar nos resultados obtidos. $\mathrm{Na}$ obra escrita por Tomelin, foram encontradas 53 ocorrências para agência de viagens e somente 1 ocorrência de agência de viagem, e na obra organizada por Braga, o primeiro termo aparece 145 vezes (sem contar os outros termos que dele derivam) e o segundo, 58. Entretanto, como não há uma normalização na linguagem do Turismo, observou-se que, por mais que um determinado acadêmico de Turismo privilegie um dos termos em detrimento do outro, pode acabar por utilizar os dois, indistintamente, no mesmo texto, e até, na mesma página, como pode ser observado na obra organizada por Braga, em que Santos e Murad Jr. usam, indiscriminadamente, o termo agência de viagens e o termo agência de viagem:

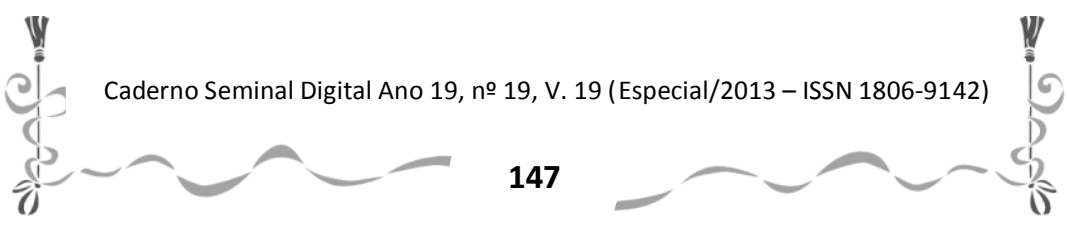




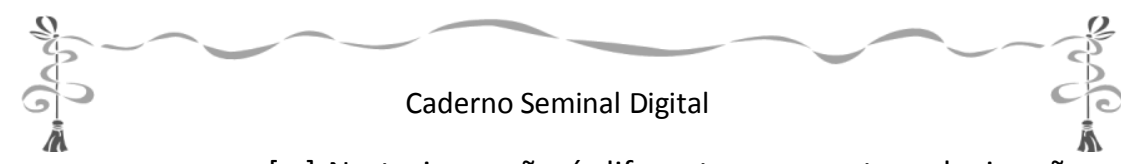

[...] No turismo não é diferente e novas tecnologias são desenvolvidas para melhorar a produtividade e a eficácia das <agências de viagens> [...] As <agências de viagem> se extinguirão? [...] Internet versus <agências de viagem>: ameaça ou oportunidade? (2007, p. 111).

A partir dessas evidências, poder-se-ia refletir se há uma diferença de sentido entre agência de viagem e agência de viagens. Faz, de fato, alguma diferença uma empresa dedicar-se a viagem (ramo de negócios, assim como agência de publicidade) ou viagens (prestação de serviço, assim como agência de empregos)? Aparentemente, não, e talvez esse seja o motivo pelo qual os acadêmicos facilmente trocam um pelo outro. Cabe destacar que os termos equivalentes em espanhol e italiano, respectivamente, são agencia de viajes e agenzia di viaggi, ambos possuindo o terceiro elemento do sintagma no plural, assim como o termo preferencial em português, agência de viagens.

Ainda a propósito do termo agência de viagens, em vários momentos dos textos analisados, este é substituído por termos equivalentes, embora estes últimos não possam ser considerados sinônimos perfeitos, visto que não são intercambiáveis em todos as situações, apresentando algumas sutis diferenças entre si. Assim sendo, na microestrutura do dicionário terminológico que será apresentado na tese de doutorado em questão, para o verbete agência de viagens, além do sinônimo perfeito agência de viagem - sobre o qual já se discorreu - aparecem também outros seis sinônimos

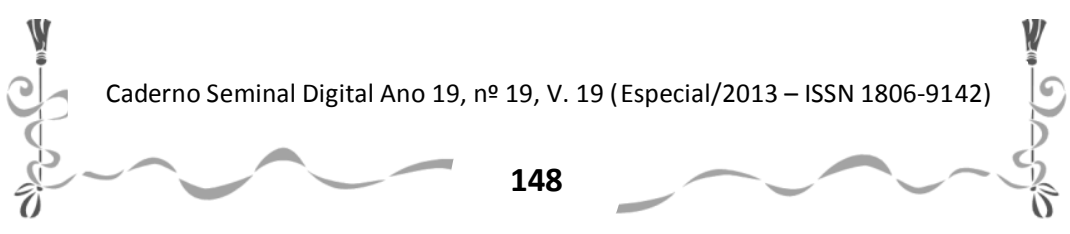


complementares (agência detalhista; agência distribuidora; agência intermediadora; agência minorista; agência varejista; agência vendedora), os quais recebem a denominação de "complementar" por serem menos importantes que o termo preferencial, que neste caso específico, é o termo agência de viagens, o que os autores mais usam. É possível dizer que todos esses sinônimos complementares podem ser substituídos pelo termo agência de viagens, o que configura a situação de sinonímia. Destaca-se que, nos idiomas estrangeiros investigados, também se encontraram sinônimos: em inglês (2 termos: travel agency; retailer); em espanhol (3 termos: agencia de viajes; agencia de viajes minorista; agencia de viajes vendedora) e em italiano (4 termos: agenzia di viaggi; agenzia di viaggi dettagliante; dettagliante; retailer), de onde se conclui que o fenômeno da sinonímia na linguagem do Turismo também se apresenta nos idiomas estrangeiros selecionados.

Avançando na discussão, no que tange à qualificação das agências, constata-se que, quando se acrescenta um adjetivo ao termo puro (sintagma simples), um caso que merece destaque é o do sintagma composto agência especializada. Antes, cabe esclarecer que o termo agência, sem nenhum outro elemento que o qualifique, pode ser interpretado de duas maneiras: i) empresa que tem somente a função de intermediar os produtos e serviços produzidos pela operadora turística, ou ainda, de elaborar seus próprios

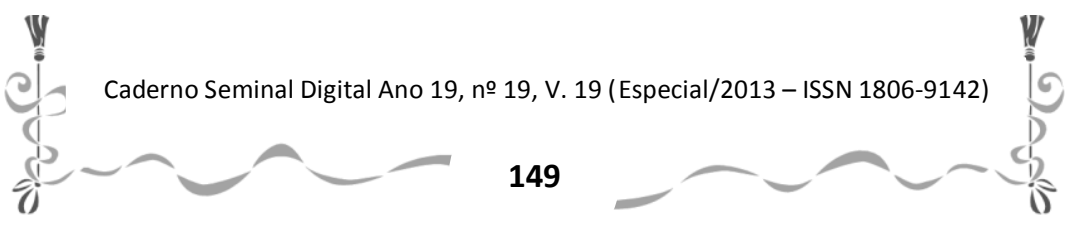


Caderno Seminal Digital

î

pacotes, desde que estes tenham pouca complexidade; ii) empresa que, efetivamente, desenvolve os pacotes turísticos, combinando, para este fim, uma série de elementos (transporte, hospedagem, alimentação, passeios, bilhetes para atrações, entretenimento, guias, etc.), em território nacional ou no exterior. $O$ trecho de uma das obras investigadas, que aqui se reproduz, deixa claro essa ambiguidade:

De maneira geral, no setor de turismo, as <agências> e <operadoras> trabalham com uma quase infinidade de fornecedores. Mesmo as <agências especializadas> em determinado setor, que supostamente trabalhariam com fornecedores específicos, ainda assim têm isso muito pulverizado, já que cada hotel, cada receptivo, cada companhia aérea é um fornecedor (TAVARES, 2007, p. 242).

Quando Tavares diz que "as agências e operadoras trabalham com uma quase infinidade de fornecedores", e, logo em seguida, acrescenta que "mesmo as agências especializadas em determinado setor, que supostamente trabalhariam com fornecedores específicos, ainda assim têm isso muito pulverizado", evidencia a duplicidade do termo agência especializada. Desta maneira, chegou-se à conclusão que, em virtude de seu duplo sentido, a apresentação deste verbete, agência especializada, não poderia deixar de evidenciar essa dupla acepção, o que resultou na decisão de associar dois sinônimos complementares: agência de viagens especializada e operadora especializada, relativos ao primeiro

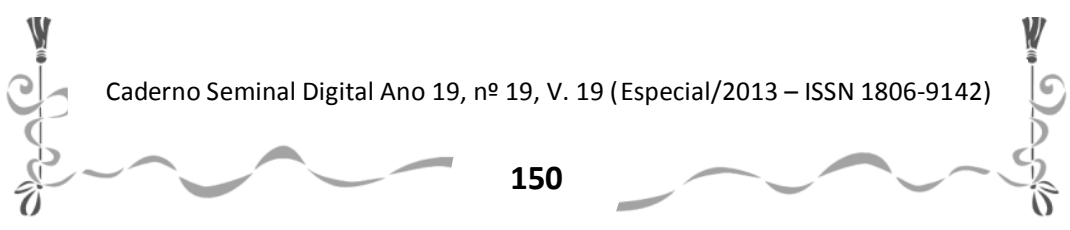


Caderno Seminal Digital

e ao segundo sentido do hiperônimo agência, conforme explicado no parágrafo anterior.

Há de se considerar, entretanto, que nem toda associação de palavras envolvendo o termo agência resulta, de fato, em um único sintagma composto. No seguinte agrupamento: agência preponderantemente produtora, os elementos agência e produtora estão separados pelo advérbio preponderantemente, o que comprova que a inserção de um advérbio entre um elemento e outro do sintagma composto não se incorpora a esse, mas somente indica a intensidade do segundo elemento, ou seja, entende-se que a agência em questão realiza bem mais atividades como produtora do que como intermediadora/vendedora.

\section{CONCLUSÕES}

Ao longo da pesquisa, encontrou-se, de fato, um amplo número de sinônimos, que estarão identificados, no dicionário terminológico de Agenciamento de Viagens e Turismo, o qual conforme já se esclareceu neste texto - é o objetivo prático da já mencionada tese de doutorado. Nesse dicionário, os sinônimos estarão identificados como sinônimos e parassinônimos. Estes últimos, por sua vez, aparecerão como sinônimos complementares, uma vez que o termo em evidência é o termo preferencial, que aparecerá com a respectiva definição e equivalências nos idiomas estrangeiros (inglês, espanhol e italiano), e os demais, isto é, os

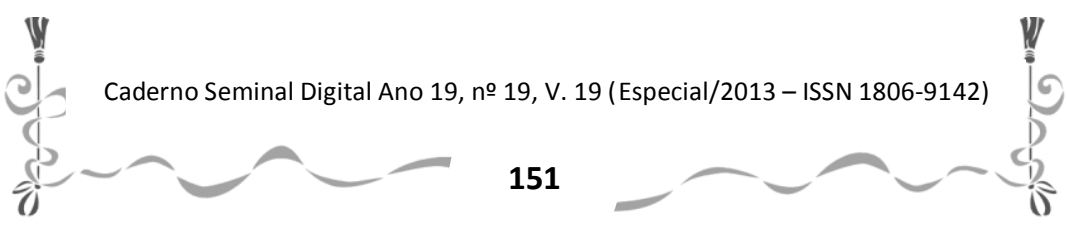


Caderno Seminal Digital

parassinônimos, aparecerão como sinônimos complementares. A microestrutura, sobre a qual já se discorreu no item Discussão dos Resultados, evidencia que, assim como há um relevante uso de sinônimos em português, o mesmo se comprova quando se analisa as ocorrências em espanhol e italiano, pois para o termo agência de viagens, visualizam-se 1 sinônimo em inglês, 2 em espanhol e 3 em italiano, conforme se comprova na tabela 3.

\begin{tabular}{|c|c|c|c|c|}
\hline & PORTUGUÊS & INGLÊS & ESPANHOL & ITALIANO \\
\hline TERMO & $\begin{array}{l}\text { agência de } \\
\text { viagens }\end{array}$ & $\begin{array}{l}\text { travel } \\
\text { agency }\end{array}$ & $\begin{array}{l}\text { agencia de } \\
\text { viajes }\end{array}$ & $\begin{array}{l}\text { agenzia di } \\
\text { viaggi }\end{array}$ \\
\hline SIN. 1 & $\begin{array}{l}\text { agência de } \\
\text { viagem }\end{array}$ & retailer & $\begin{array}{l}\text { agencia de } \\
\text { viajes } \\
\text { minorista }\end{array}$ & $\begin{array}{l}\text { agenzia di } \\
\text { viaggi } \\
\text { dettagliante }\end{array}$ \\
\hline SIN. 2 & $\begin{array}{l}\text { agência } \\
\text { detalhista }\end{array}$ & & $\begin{array}{l}\text { agencia de } \\
\text { viajes } \\
\text { vendedora }\end{array}$ & dettagliante \\
\hline SIN. 3 & $\begin{array}{l}\text { agência } \\
\text { distribuidora }\end{array}$ & & & retailer \\
\hline SIN. 4 & $\begin{array}{l}\text { agência } \\
\text { intermediadora }\end{array}$ & & & \\
\hline SIN. 5 & $\begin{array}{l}\text { agência } \\
\text { minorista }\end{array}$ & & & \\
\hline SIN. 6 & agência varejista & & & \\
\hline SIN. 7 & $\begin{array}{l}\text { agência } \\
\text { vendedora }\end{array}$ & & & \\
\hline
\end{tabular}

Tabela 3: Sinônimos do termo agência de viagens, em português, inglês, espanhol e italiano.

Caderno Seminal Digital Ano 19, no 19, V. 19 (Especial/2013 - ISSN 1806-9142) 
Caderno Seminal Digital

A propósito da segunda hipótese, nesta parte específica da pesquisa, a qual tem como escopo a análise do termo agência e de seus derivados, registraram-se somente 2 ocorrências de antônimos. O primeiro associa-se à atuação da agência no que diz respeito ao seu caráter de enviar turistas a outras regiões ou países, ou, ao contrário, de receber turistas de outras regiões ou países, resultando em dois termos antônimos: agência emissiva e agência receptiva. A segunda ocorrência de antonímia traduz um fenômeno bastante recente, posto que, com o advento da Internet, as empresas dos mais distintos setores passaram a vislumbrar esse novo ambiente como uma possibilidade de comercializar seus produtos diretamente aos consumidores finais, eliminando, ou ao menos reduzindo, o número de lojas físicas. Com a atividade de agenciamento não foi diferente, e muitas agências, dos mais variados tipos, lançaram suas agências virtuais, em contraposição com as já consolidadas (e talvez um pouco obsoletas) agências físicas. Tal contraposição evidencia a situação de antonímia, uma vez que no caso desta (física), os clientes precisam se deslocar até a loja da agência para realizar parte ou todas as suas atividades, embora também haja, neste caso, a possibilidade de contato telefônico e através da internet, mas, se quiserem, os clientes podem interagir pessoalmente com os agentes. No caso da agência virtual, por outro lado, todas as transações são realizadas exclusivamente no ambiente da Internet, sem quaisquer contatos pessoais.

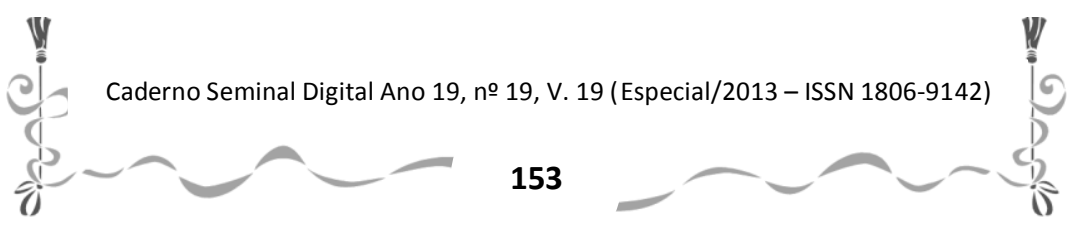


Com relação à terceira hipótese, verificou-se uma discreta influência do idioma espanhol, no que concerne aos termos derivados de agência, em ambas as obras analisadas. Tomelin (2001, pp. 24-25) apresenta uma tipologia das agências de turismo, baseada no sistema espanhol/mexicano, no qual se inspirou. Nesta tipologia, distinguem-se seis tipos distintos: agências de viagens detalhistas; agências de viagens maioristas; agências de viagens tour operators (operadoras de turismo); agências de viagens receptivas; agências de viagens e turismo consolidadoras e agências de viagens e turismo escola. Entretanto, além dos tipos de agências que derivam dessa tipologia, o autor também apresentou os seguintes termos: atacadistas; agência-laboratório; agência tradicional; agência via internet e agências (empresas) virtuais. A influência da língua espanhola verifica-se, particularmente, nos termos que denotam um empréstimo linguístico, e consequente adaptação, deste idioma: agência detalhista, que é a adaptação do termo espanhol detallista, e é o mesmo que varejista, isto é, significa a agência de viagens vendedora, intermediadora, e cujo antônimo é agência maiorista, adaptação do termo mayorista, que quer dizer atacadista, ou melhor, operadora turística, que, na prática, é a agência produtora, ou seja, a que produz os pacotes turísticos. Também no texto de Braga (2007b), verificaram-se ocorrências de alguns desses termos, que receberam influência da língua espanhola: agência maiorista; agência minorista e agência maiorista-minorista, a qual, segundo

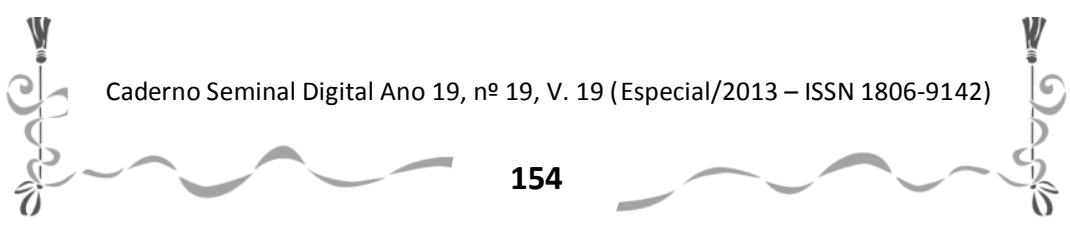


Caderno Seminal Digital

卒

Braga, é aquela que "pode, simultaneamente, funcionar como maiorista e minorista, com pontos de venda próprios" (2007b, p. 21). Faz-se necessário esclarecer, contudo, que no sistema brasileiro, corroborado pelo Ministério do Turismo, através da Lei Nacional do Turismo, há somente três tipos: agência de turismo, que engloba qualquer tipo de agência de atuação e comercialização no âmbito do turismo; agência de viagens e turismo - também conhecida popularmente como operadora turística, que seria a empresa que pesquisa, elabora, compõe, formata e comercializa os pacotes turísticos diretamente ao consumidor final, ou através de agências de viagens intermediadoras, e a agência de viagens, que atua como intermediadoras entre os fornecedores (companhias aéreas, meios de hospedagem, estabelecimentos de alimentação, casas de espetáculos, empresas de seguro, operadoras turísticas, etc.) e o consumidor final, e como consultores, assessorando e aconselhando seus clientes. Conclui-se, portanto, que a diferença entre o sistema espanhol/mexicano e o brasileiro e, consequentemente, a terminologia resultante, reflete uma visão de mundo distinta no que concerne à atividade de Agenciamento de Viagens e Turismo. Consequentemente, a hipótese 3 só pode ser confirmada parcialmente, pois influência existe, mas não é muito extensiva.

Não se verificou influência significativa do idioma inglês, como se havia pensado quando se apresentou a

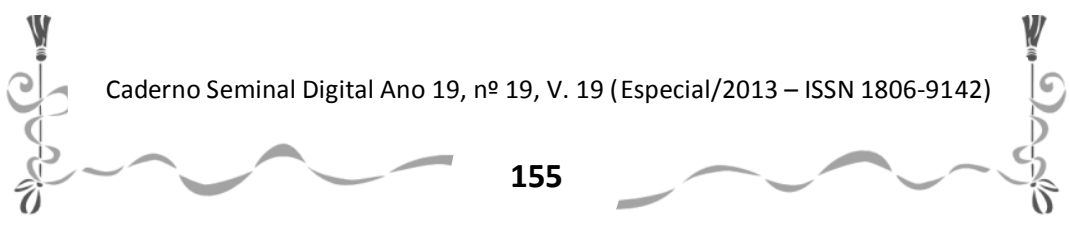


hipótese 4. Ainda que a influência desse idioma seja importante na terminologia da linguagem do Turismo e na sua subárea Agenciamento de Viagens e Turismo, especificamente no que tange aos termos derivados do hiperônimo agência, tal influência não se comprovou. Todavia, embora no português brasileiro, tenha se notado que a influência da língua inglesa não é significativa no que diz respeito ao termo agência, no italiano verificou-se exatamente o contrário, já que há uma abundância de termos emprestados do inglês, conforme comprova a tabela 4, que contrapõe alguns termos em português, com seus equivalentes em inglês, espanhol e italiano, sendo que este último idioma é o que mais abriga termos emprestados do língua inglesa ou formações híbridas com algum dos elementos do sintagma composto em inglês.

\begin{tabular}{|c|c|c|c|}
\hline $\begin{array}{l}\text { TERMO EM } \\
\text { PORTUGUÊS } \\
\text { BRASILEIRO }\end{array}$ & $\begin{array}{l}\text { TERMOS EM } \\
\text { INGLÊS }\end{array}$ & $\begin{array}{ll}\text { TERMOS } & \text { EM } \\
\text { ESPANHOL } & \end{array}$ & $\begin{array}{l}\text { TERMOS } \\
\text { ITALIANO }\end{array}$ \\
\hline $\begin{array}{l}\text { Agência } \\
\text { viagens }\end{array}$ & $\begin{array}{l}\text { travel } \\
\text { agency; } \\
\text { retailer }\end{array}$ & $\begin{array}{l}\text { agencias de } \\
\text { viajes; agencia } \\
\text { de viajes } \\
\text { minorista; } \\
\text { agencia de viajes } \\
\text { vendedora }\end{array}$ & $\begin{array}{lll}\text { agenzia di viaggi } \\
\text { agenzia di } & \text { viaggi } \\
\text { dettagliante; } & \\
\text { dettagliante; } & \text { retailer }\end{array}$ \\
\hline $\begin{array}{l}\text { Agência } \\
\text { emissiva }\end{array}$ & $\begin{array}{l}\text { outgoing } \\
\text { agency }\end{array}$ & agencia emissora & $\begin{array}{lr}\begin{array}{l}\text { agenzia di } \\
\text { outgoing }\end{array} & \text { (termo } \\
\text { híbrido) } & \end{array}$ \\
\hline $\begin{array}{l}\text { Agência } \\
\text { receptiva }\end{array}$ & $\begin{array}{l}\text { Incoming } \\
\text { agency }\end{array}$ & $\begin{array}{l}\text { agencia } \\
\text { receptiva }\end{array}$ & $\begin{array}{lrr}\text { agenzia di } & \text { turismo } \\
\text { incoming } & \text { (termo }\end{array}$ \\
\hline
\end{tabular}

Caderno Seminal Digital Ano 19, no 19, V. 19 (Especial/2013 - ISSN 1806-9142)

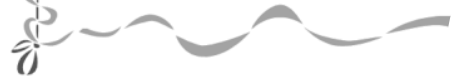




\begin{tabular}{|l|l|l|l|}
\hline & & híbrido) \\
\hline Agência física & $\begin{array}{l}\text { off-line } \\
\text { agency }\end{array}$ & $\begin{array}{l}\text { agencia de viajes } \\
\text { fisica }\end{array}$ & $\begin{array}{l}\text { agenzia off line } \\
\text { (termo híbrido) }\end{array}$ \\
\hline Agência virtual & $\begin{array}{l}\text { on-line } \\
\text { agency }\end{array}$ & $\begin{array}{l}\text { agencia de viajes } \\
\text { on-line }\end{array}$ & $\begin{array}{l}\text { agenzia on line } \\
\text { (termo híbrido) ou } \\
\text { web agency }\end{array}$ \\
\hline Agente Geral & $\begin{array}{l}\text { General } \\
\text { Sales Agent }\end{array}$ & $\begin{array}{l}\text { Agente General } \\
\text { de Ventas }\end{array}$ & $\begin{array}{l}\text { GSA (General Sales } \\
\text { Agent) }\end{array}$ \\
\hline
\end{tabular}

Tabela 4: Termos em português, com seus equivalentes em inglês, espanhol e italiano, evidenciando a influência do inglês nos equivalentes italianos.

Analisando a tabela 4, constata-se que há dois tipos de termos italianos que denotam a influência do inglês; aqueles que, simplesmente, adotaram um termo da língua inglesa, através de empréstimos, como é o caso dos termos retailer, web agency e General Sales Agent, e os que apresentam formações híbridas, em que parte do sintagma é formada por um vocábulo em italiano e parte formada por um ou mais vocábulos em inglês, como se observa nos sintagmas agenzia di turismo incoming; agenzia di turismo outgoing, agenzia on line; agenzia off line. Seria interessante, num futuro estudo, analisar se esses termos italianos, tomados como empréstimo da língua inglesa, ou de formação híbrida, são compreensíveis a todos os clientes potenciais das agências de turismo daquele país e aos clientes estrangeiros em viagem à Itália, os quais, eventualmente, possam usar os serviços incoming das agências italianas, pois, conforme observa Sager (2003), o uso

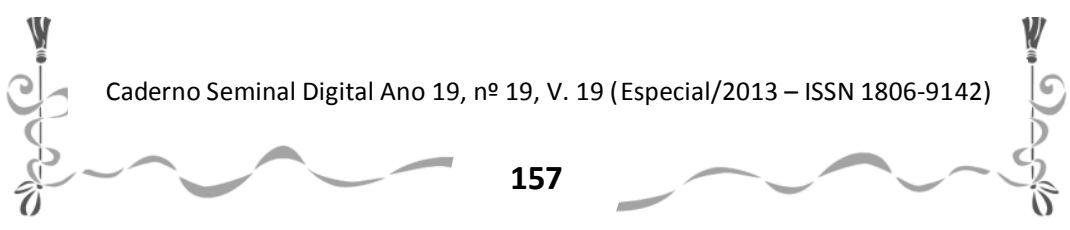


da/das terminologia/s pode ser um obstáculo para a compreensão, sempre que o destinatário não possua um conhecimento adequado da linguagem setorial utilizada.

À guisa de conclusão, confirma-se a hipótese 1, pois, de fato, há um amplo uso de sinônimos nos quatro idiomas analisados, embora tenha sido registrado um número maior de ocorrências em português. Confirma-se a hipótese 2, somente parcialmente, pois há casos de antonímia, mas não em grande número. Da mesma forma, confirma-se apenas parcialmente a hipótese 3 , pois embora haja uma discreta influência do idioma espanhol, tal influência mostrou-se pouco significativa. Rejeita-se a hipótese 4 , considerando que, no que tange à análise que o presente trabalho se propôs a fazer, tendo como foco o termo agência e seus derivados, em português brasileiro, não se comprovou influência da língua inglesa. Ressalta-se, entretanto, que para os mesmos termos e derivados, a influência do inglês mostrou-se bastante significativa nos termos em italiano, porém, como a língua que deve ser o foco deste estudo é o português, a hipótese teve de ser rejeitada. A tabela 5 evidencia melhor a conclusão para cada hipótese que norteou o trabalho.

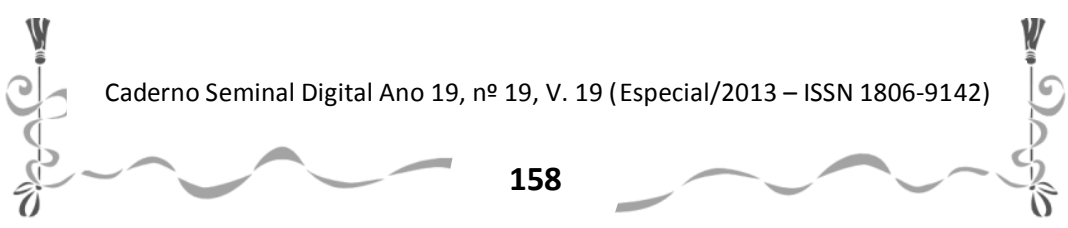




\begin{tabular}{|l|c|c|c|}
\hline & CONFIRMADA & $\begin{array}{l}\text { CONFIRMADA } \\
\text { PARCIALMENTE }\end{array}$ & $\begin{array}{l}\text { NÃO } \\
\text { CONFIRMADA }\end{array}$ \\
\hline $\begin{array}{l}\text { Hipótese } \\
\text { número 1 }\end{array}$ & $\mathrm{X}$ & $\mathrm{X}$ & \\
\hline $\begin{array}{l}\text { Hipótese } \\
\text { número 2 }\end{array}$ & & $\mathrm{X}$ & \\
\hline $\begin{array}{l}\text { Hipótese } \\
\text { número 3 }\end{array}$ & & & $\mathrm{X}$ \\
\hline $\begin{array}{l}\text { Hipótese } \\
\text { número 4 }\end{array}$ & & & \\
\hline
\end{tabular}

Tabela 5: Resultado das hipóteses analisadas.

Por fim, poder-se-iam conduzir estudos semelhantes para cada hiperônimo associado à subárea de Agenciamento de Viagens e Turismo, visto que esta é profícua de relações de sinonímia, e de acordo com a Teoria Comunicativa da Terminologia, que, ao que se viu, não se propõe prescritiva, mas sim descritiva, haveria ainda uma série de relações a serem estabelecidas através do estudo mais aprofundado de observação e descrição da sinonímia para essa subárea.

\section{REFERÊNCIAS BIBLIOGRÁFICAS}

BRAGA, D. C. (Org.) (2007a). Agências de Viagens e Turismo: Práticas de Mercado. Rio de Janeiro: Elsevier/Campus.

BRAGA, D. C. (2007b). Discussão Conceitual e Tipologias das Agências de Turismo. In: In: BRAGA, D. C. (Org.). Agências de Viagens e Turismo: Práticas de Mercado. Rio de Janeiro: Elsevier/Campus.

Caderno Seminal Digital Ano 19, no 19, V. 19 (Especial/2013 - ISSN 1806-9142)

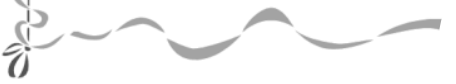


Caderno Seminal Digital

BRAGA, R. (2003). Dicionário de Turismo. São Paulo: Uniletras.

Diccionari D'Hoteleria i Turismo Termcat. TERMCAT, Centre de Terminologia/Edicions 62: Barcelona, 2001.

SAGER, J. C. (1993). La terminología, puente entre varios mundos (Prólogo). In: CABRÉ, M. T. (Org.). La terminología. Teoría, metodología, aplicaciones, Antártida/Empúries, Barcelona.

SANTOS, C. M. \& MURAD JR. E. W (2007). Sistemas de Reservas e ECommerce. In: BRAGA, D. C. (Org.). Agências de Viagens e Turismo: Práticas de Mercado. Rio de Janeiro: Elsevier/Campus.

SARDINHA, T. B. (2004). Linguística de Corpus. Manole: Barueri (SP).

TAVARES, A. (2007). Mercado de Intercâmbio. In: BRAGA, D. C. (Org.). Agências de Viagens e Turismo: Práticas de Mercado. Rio de Janeiro: Elsevier/Campus.

TOMELIN (2001), Carlos Alberto. Mercado de Agências de Viagens e Turismo: como competir diante de novas tecnologias. São Paulo: Aleph.

\section{OUTRAS FONTES}

BARBOSA, M. A. (s/d). A construção do conceito nos discursos técnico-científicos, nos discursos literários e nos discursos sociais não-literários. Disponível em: <pt.scribd.com/doc/98467982/ArtigoMaria-Aparecida-Barbosa>. Acesso em 24/11/2010.

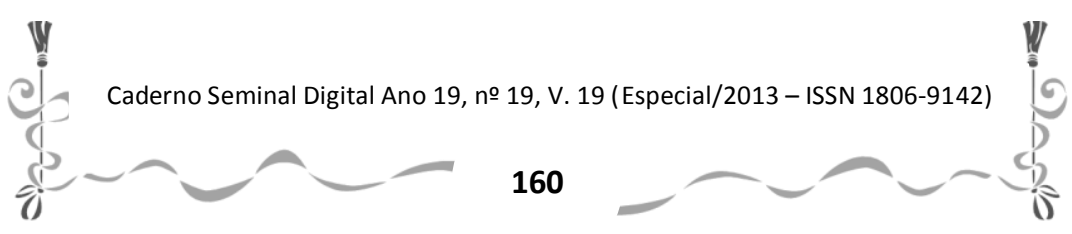

